\title{
Use of continuous negative pressure around the chest increases exercise performance in chronic obstructive pulmonary disease patients: A pilot study
}

\author{
Rakesh K Chaturvedi MD PhD ${ }^{1}$, Arnold Zidulka MD FRCP ${ }^{2}$
}

RK Chaturvedi, A Zidulka. Use of continuous negative pressure around the chest increases exercise performance in chronic obstructive pulmonary disease patients: A pilot study. Can Respir J 2011;18(1):e6-e9.

BACKGROUND: Patients with severe chronic obstructive pulmonary disease (COPD) often have intrinsic positive end-expiratory pressure. Continuous positive airway pressure has been shown to decrease the inspiratory work of breathing and increases exercise capacity in these patients. OBJECTIVE: To determine whether continuous negative pressure (CNP) around the chest is able to bring the positive end-expiratory pressure closer to atmospheric pressure, thereby reducing the threshold load and increasing exercise capability.

METHODS: A pilot study was undertaken with eight COPD patients who had been hospitalized for exacerbation and were close to discharge. For CNP, a shell (around the thorax from under the axillae to the mid abdomen) and wrap were used. Each of the eight patients was assessed with a 6 min walk test in three modes (in randomized order) with 30 min of rest in between: a control walk with no shell or wrap; a sham CNP in which the applied CNP was negligible; and CNP, with pressure chosen by the patient that provided maximal relief of dyspnea at rest.

RESULTS: At the end of each of the 6 min walk tests, there was no difference in heart rate, oxygen saturation or level of dyspnea among the three test modes. Respiratory rate was reduced with CNP compared with sham. The patients walked furthest with CNP compared with control (mean \pm SD) $(313 \pm 66.2 \mathrm{~m}$ versus $257 \pm 65.2 \mathrm{~m} ; \mathrm{P}<0.01)$ and compared with sham.

CONCLUSIONS: In the present pilot study, COPD patients improved their exercise performance with CNP.

Key Words: 6 min walk test; Continuous negative pressure; Continuous positive airway pressure; Exercise performance

$\mathrm{C}$ hronic obstructive pulmonary disease (COPD) patients may develop hyperinflation and intrinsic positive end-expiratory pressure (PEEPi) (1-3). This is more likely to occur during exercise when the respiratory rate is increased $(4,5)$, which results in a major increase in the inspiratory work of breathing and, consequently, may limit exercise capability.

The application of continuous positive airway pressure (CPAP) at the airway opening has been shown to decrease the inspiratory work of breathing in patients with expiratory airflow limitation and PEEPi (1). During exercise, O'Donnell et al (6) showed that the application of CPAP in COPD patients resulted in a significant increase in exercise endurance and reduced dyspnea.

We have previously shown that continuous negative pressure (CNP) is equivalent to CPAP in acutely ill patients with COPD in the intensive care unit (7). We reasoned that CNP around the chest wall might reduce PEEPi and thereby increase exercise capability in COPD patients. Instead of CPAP reducing the threshold load in patients with PEEPi (Figure 1), CNP would cause the PEEPi to be closer to atmospheric pressure (Figure 1). The advantage of CNP over CPAP would be that the patient might be able to walk without a tight-fitting mask applied to the face.
L'utilisation de la pression négative continue autour du thorax accroît le rendement à l'exercice chez les patients atteints de maladie pulmonaire obstructive chronique : une étude pilote

HISTORIQUE : Les patients atteints de maladie pulmonaire obstructive chronique $(\mathrm{MPOC})$ ont souvent une pression positive intrinsèque en fin d'expiration. Il est démontré que la pression positive continue réduit le travail inspiratoire et accrôtt la capacité à l'exercice chez ces patients.

OBJECTIF : Déterminer si la pression négative continue (PNC) autour du thorax peut rapprocher la pression positive en fin d'expiration de la pression atmosphérique, réduisant ainsi la charge seuil et accroissant la capacité à l'exercice.

MÉTHODOLOGIE : Les chercheurs ont entrepris une étude pilote auprès de huit patients atteints de MPOC hospitalisés en raison d'une exacerbation et qui devaient bientôt obtenir leur congé. Pour susciter la PNC, ils utilisaient une coquille (autour du thorax, entre les aisselles et le milieu de l'abdomen) et des bandages. Chacun des huit patients était évalué dans le cadre d'une épreuve de marche de six minutes reprise de trois façons (dans un ordre aléatoire) séparées par une période de repos de 30 minutes : une marche témoin sans coquille ni bandage, une PNC placebo au cours de laquelle la PNC appliquée était négligeable et une PNC dont la pression était sélectionnée par le patient afin d'assurer un soulagement maximal de la dyspnée au repos.

RÉSULTATS : À la fin de chaque épreuve de marche de six minutes, on ne remarquait pas de différence de fréquence cardiaque, de taux de saturation en oxygène ou de dyspnée dans les trois modes de l'épreuve. La fréquence respiratoire était moins élevée avec la PNC qu'avec un dispositif placebo. Les patients parcouraient une plus grande distance avec la PNC que les sujets témoins (moyenne \pm ÉT) $(313 \pm 66,2 \mathrm{~m}$ par rapport à $257 \pm 65,2 \mathrm{~m} ; \mathrm{P}<0.01)$ et que ceux qui utilisaient un dispositif placebo.

CONCLUSIONS : Dans la présente étude pilote, les patients atteints de MPOC ont amélioré leur rendement à l'exercice grâce à la PNC.

For the present pilot study, we constructed a lightweight shell and jacket to surround a patient's chest wall and applied CNP underneath the shell while the patient exercised. We compared results in the same patient exercising with and without the shell, and with a sham negative pressure.

\section{METHODS}

Eight hospitalized patients (six men and two women) were recruited to participate in the study. All patients had been admitted for an exacerbation of COPD. All patients had improved at the time of the study and were close to being discharged. Patients with cardiac disease were excluded, as were patients with illnesses that limited them from exercising (eg, arthritic or neurological diseases). The protocol was approved by the hospital's ethics committee and written consent was obtained from each patient before they entered the study.

A lightweight $(0.90 \mathrm{~kg})$, hard shell with a front door (to allow the patient to enter the shell) was constructed. The shell surrounded the patient from just under the axilla to the upper abdomen and was held in place by shoulder straps. To create an airtight seal, a commercially available nylon jacket $(90 \mathrm{~g})$ was used over the shell. A hole in the front of the jacket and the shell facilitated connection to a suction port so that

${ }^{1}$ Divisions of Cardiac Surgery and Critical Care, Royal Victoria Hospital; ${ }^{2}$ Division of Respiratory Medicine and Intensive Care Medicine,

Montreal General Hospital and Montreal Chest Institute, McGill University Health Centre, Montreal, Quebec

Correspondence: Dr Arnold Zidulka, Montreal General Hospital, Division of Respiratory Medicine, 1650 Cedar Avenue, LH 10-412, Montreal,

Quebec H3G 1A4. Telephone 514-934-1934 ext 48014, fax 514-934-8226, e-mail arnold.zidulka@muhc.mcgill.ca 


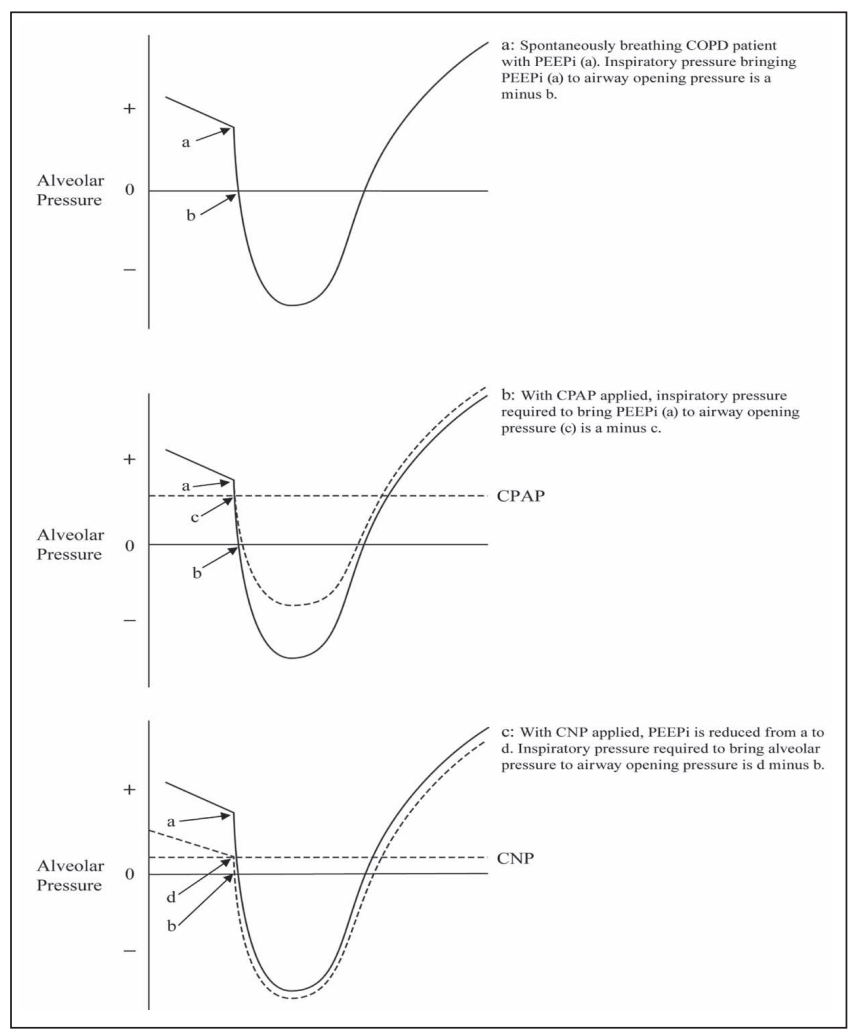

Figure 1) Schematic diagram showing the mechanism of action of continuous positive airway pressure (CPAP) and continuous negative pressure (CNP). COPD Chronic obstructive pulmonary disease; PEEPi Intrinsic positive end-expiratory pressure

negative pressure could be created under the shell. As the suction was applied, the nylon jacket was sucked against the body to make the shell air-tight at the neck, waist and arms. CNP was produced by a modified ventilator (Thompson MV Maxivent, Puriton-Bennett Corporation, USA). With the use of a catheter and pressure transducer, the suction pressure under the shell during the application of CNP was measured.

Patients were initially tested at rest with different levels of negative pressure to determine the amount of negative pressure that was most comfortable for breathing. Negative pressures ranging from $0 \mathrm{cmH}_{2} \mathrm{O}$ to $-40 \mathrm{cmH}_{2} \mathrm{O}$ (in increments of $5 \mathrm{cmH}_{2} \mathrm{O}$ ) and from $-40 \mathrm{cmH}_{2} \mathrm{O}$ to $\mathrm{O} \mathrm{cmH}_{2} \mathrm{O}$ were applied under the shell and jacket. Approximately four breaths were allowed at each level of negative pressure. The pressure at which the patient was most comfortable breathing at rest was chosen to perform the 6 min walk test.

To determine whether a change in the level of functional residual capacity $(\triangle \mathrm{FRC})$ occurred at rest with the application of the most comfortable CNP, a bag-in-a-box system with a spirometer (8) was used and tidal volume was measured. While the patient was breathing quietly at rest, CNP was suddenly applied. The $\triangle \mathrm{FRC}$ was recorded as the change in the end-expiratory level (using the slope of the curve of FRC pre and post CNP application). In addition, the inspiratory capacity (IC) was measured with and without the application of CNP in the steady state and any change (ie, $\Delta \mathrm{IC}$ ) was noted.

The patients then underwent three 6 min walks tests: control without shell and jacket; shell and jacket worn with a sham CNP of -2 $\mathrm{cmH}_{2} \mathrm{O}$ applied; and shell and jacket worn with the most comfortable CNP applied. The order of these three walk tests was randomized for each patient. There was $30 \mathrm{~min}$ of rest between each of the $6 \mathrm{~min}$ walks. Two of the patients received oxygen at rest; the same level of administered oxygen was maintained during their 6 min walk test. No bronchodilators were given for $1 \mathrm{~h}$ before nor once the $6 \mathrm{~min}$ walk tests were started.
TABLE 1

Demographics, diagnosis and pulmonary function data

\begin{tabular}{|c|c|c|c|c|c|c|}
\hline Patient & $\begin{array}{l}\text { Age, } \\
\text { years }\end{array}$ & Sex & Diagnosis & $\begin{array}{c}\text { Baseline } \mathrm{FEV}_{1} \text {, } \\
\% \text { predicted }\end{array}$ & $\begin{array}{c}\text { FVC, } \\
\% \text { predicted }\end{array}$ & $\begin{array}{c}\text { FEV }_{1} \\
\times 100 / \\
\text { FVC, } \% \\
\end{array}$ \\
\hline 1 & 70 & Male & $\begin{array}{l}\text { Asthma/ } \\
\text { COPD }\end{array}$ & 26 & 59 & 34 \\
\hline 2 & 60 & Male & COPD & 25 & 62 & 32 \\
\hline 3 & 80 & Female & COPD & 66 & 86 & 56 \\
\hline 4 & 65 & Male & COPD & 20 & 39 & 41 \\
\hline 5 & 53 & Male & COPD & 43 & 72 & 49 \\
\hline 6 & 55 & Female & $\begin{array}{l}\text { Asthma/ } \\
\text { COPD }\end{array}$ & 20 & 69 & 25 \\
\hline 7 & 81 & Male & COPD & 19 & 45 & 41 \\
\hline 8 & 63 & Male & COPD & 28 & 69 & 32 \\
\hline
\end{tabular}

COPD Chronic obstructive pulmonary disease; FEV 1 Forced expiratory volume in $1 \mathrm{~s}$; FVC Forced vital capacity

The 6 min walk test was conducted in an unblinded fashion in a hospital corridor with the patient walking back and forth between two markers $32 \mathrm{~m}$ apart. To maintain the negative pressure under the shell, an investigator walked behind the patient with the apparatus on a cart attached to an electrical cord $50 \mathrm{~m}$ long to provide power for CNP. During each walk, the patient was continuously encouraged to walk as quickly as possible. At the end of each 6 min walk, respiratory rate (RR), heart rate (HR) and oxygen saturation were measured immediately. The modified Borg scale (9) was used to measure dyspnea at the beginning and end of each of the walk tests.

Because the patients served as their own control, repeated measures ANOVA was used for statistical analysis (InStat, GraphPad Software Inc, USA). In addition to the $6 \mathrm{~min}$ walk, a multiple comparison was performed after the test to reduce the overall chance of a spurious significant difference. A Tukey-Kramer multiple comparison test and Bonferroni multiple comparison test were also conducted. Group data are presented as mean \pm SD.

\section{RESULTS}

The patients' age ranged from 53 to 81 years (Table 1 ). The baseline forced expiratory volume in $1 \mathrm{~s}\left(\mathrm{FEV}_{1}\right)$ ranged from $19 \%$ to $66 \%$ of predicted (mean $31 \%$ ). The forced vital capacity (FVC) as percentage predicted is reported, as is the ratio of $\mathrm{FEV}_{1} / \mathrm{FVC}$.

The most comfortable CNP ranged from $-7 \mathrm{cmH}_{2} \mathrm{O}$ to $-33 \mathrm{cmH}_{2} \mathrm{O}$ (Table 2). Two of the patients (1 and 6) used supplemental oxygen during each of the 6 min walk tests. The $\triangle F R C$ (as measured by the bag-in-a-box method) with the application of the most comfortable CNP ranged from $-0.3 \mathrm{~L}$ to $0.4 \mathrm{~L}$. The $\Delta \mathrm{IC}$ ranged from $-0.1 \mathrm{~L}$ to $0.3 \mathrm{~L}$. Because a stable baseline breathing pattern for FRC could not be attained in patients 1 and $8, \Delta \mathrm{FRC}$ and $\Delta \mathrm{IC}$ could not be measured in these patients.

There was no change in oxygen saturation among the three ventilation modes at the end of each of the 6 min walk tests (Table 3). RR and HR decreased with the application of CNP compared with sham, but not control CNP, and there was no difference between sham and control.

With respect to the 6 min walk test, all statistical analyses produced the same results. The distance travelled during the 6 min walk test was significantly increased with CNP compared with control and sham CNP (mean of $313 \mathrm{~m}$ versus $257 \mathrm{~m}$ and $246 \mathrm{~m}$, respectively [Figure 2]). There was no significant difference in the walk distance between sham CNP and control (Table 3). There were no significant differences in the Borg scale for dyspnea at the end of each of the walks.

\section{DISCUSSION}

In the present pilot study, we demonstrated that patients were able to walk further with CNP than without. Without CNP involved either 


\begin{tabular}{|c|c|c|c|c|c|}
\hline \multirow[b]{2}{*}{ Patient } & \multirow[b]{2}{*}{ Diagnosis } & \multirow{2}{*}{$\begin{array}{c}\mathrm{CNP}, \\
\mathrm{cmH}_{2} \mathrm{O}\end{array}$} & \multirow[b]{2}{*}{$\mathrm{FiO}_{2}$} & \multicolumn{2}{|c|}{ With CNP } \\
\hline & & & & $\triangle \mathrm{FRC}, \mathrm{L}$ & $\Delta \mathrm{IC}, \mathrm{L}$ \\
\hline 1 & $\begin{array}{l}\text { Asthma/ } \\
\text { COPD }\end{array}$ & -8 & 0.28 & * & * \\
\hline 2 & COPD & -10 & 0.21 & 0.1 & 0 \\
\hline 3 & COPD & -19 & 0.21 & 0.1 & 0.1 \\
\hline 4 & COPD & -33 & 0.21 & 0.1 & 0.1 \\
\hline 5 & COPD & -10 & 0.21 & 0.1 & 0.1 \\
\hline 6 & $\begin{array}{l}\text { Asthma/ } \\
\text { COPD }\end{array}$ & -32 & $\begin{array}{l}2.5 \mathrm{~L} / \mathrm{min} \\
(\mathrm{NP})\end{array}$ & 0.4 & -0.1 \\
\hline 7 & COPD & -7 & 0.21 & -0.3 & 0.3 \\
\hline 8 & COPD & -7 & 0.21 & * & * \\
\hline
\end{tabular}

*Stable baseline for FRC and IC not attained. COPD Chronic obstructive pulmonary disease; $\mathrm{FiO}_{2}$ Fraction of inspired oxygen; NP Nasal prongs

TABLE 3

Parameters at end of the 6 min walk test

\begin{tabular}{|c|c|c|c|c|c|c|}
\hline \multirow[b]{2}{*}{ Parameter } & \multicolumn{3}{|c|}{ Ventilation mode } & \multicolumn{3}{|c|}{$\mathbf{P}$} \\
\hline & $\begin{array}{l}\text { Control } \\
\text { (A) }\end{array}$ & $\begin{array}{l}\text { Sham } \\
\text { (B) }\end{array}$ & $\begin{array}{l}\text { CNP } \\
\text { (C) }\end{array}$ & $\begin{array}{c}\text { A vs } \\
B\end{array}$ & $\begin{array}{c}\text { A vs } \\
\text { C }\end{array}$ & $\begin{array}{c}\text { B vs } \\
\text { C }\end{array}$ \\
\hline $\begin{array}{l}\text { Respiratory rate, } \\
\text { breaths/min }\end{array}$ & $27.1 \pm 4.5$ & $27.5 \pm 3.8$ & $25.5 \pm 4.0$ & ns & ns & $<0.05$ \\
\hline Heart rate, beats/min & $109 \pm 12.0$ & $113 \pm 13.8$ & $105 \pm 11.3$ & ns & ns & $<0.05$ \\
\hline Oxygen saturation, \% & $91 \pm 4.1$ & $91 \pm 4.5$ & $92 \pm 4.1$ & ns & ns & ns \\
\hline 6 min walk distance, $\mathrm{m}$ & $257 \pm 65.2$ & $246 \pm 61.5$ & $313 \pm 66.2$ & ns & $<0.01$ & $<<0.05$ \\
\hline Borg scale & $1.9 \pm 1.2$ & $2.0 \pm 0.8$ & $2.1 \pm 1.0$ & ns & ns & ns \\
\hline
\end{tabular}

Data presented as mean $\pm S D$ unless otherwise indicated. CNP Continuous negative pressure; ns Not statistically significant; vs Versus

wearing the shell and jacket (with a sham CNP applied) or not wearing the shell and jacket. The distance walked with the sham CNP was the shortest (perhaps related to the weight of the shell and jacket), although this was not statistically different from not having a shell and jacket applied.

The level of dyspnea at the end of each walk test was the same regardless of whether CNP was applied. Presumably, this is related to the fact that CNP application resulted in a greater distance walked in the 6 min period for the same dyspnea level. RR and HR were both reduced at the end of the walk only when CNP was applied.

In the current study, we did not measure expiratory muscle activity, which has been shown to occur with the application of CPAP during exercise $(4,10)$. Furthermore, we did not measure actual PEEPi. We used negative pressure under the shell at a level at which the patient subjectively felt most comfortable with respect to breathing at rest. The CNP ranged from $-7 \mathrm{cmH}_{2} \mathrm{O}$ to $-33 \mathrm{cmH}_{2} \mathrm{O}$. In all patients in whom a stable FRC baseline was attained, there were minor changes in FRC with CNP. This implied that the application of CNP did not result in significant hyperinflation and that PEEPi was probably present. If a patient did not have PEEPi, the application of CPAP and CNP would ordinarily cause hyperinflation (11-13). The decrease in respiratory rate that occurred with CNP could also have resulted in a decreased PEEPi $(4,5)$.

These results were similar to those obtained when CPAP was applied during exercise in COPD patients with PEEPi $(6,11)$. The increase in distance walked with CNP versus control was 22\% (mean $56 \mathrm{~m}$ ) while the increase in bicycle endurance with CPAP versus control was $48 \%$ (6). A hypothetical diagram explaining how CPAP functions relative to CNP is shown in Figure 1. CPAP reduces the threshold load imposed by PEEPi, while CNP would cause PEEPi to be closer to atmospheric pressure. In both cases, the inspiratory work of breathing would be reduced.

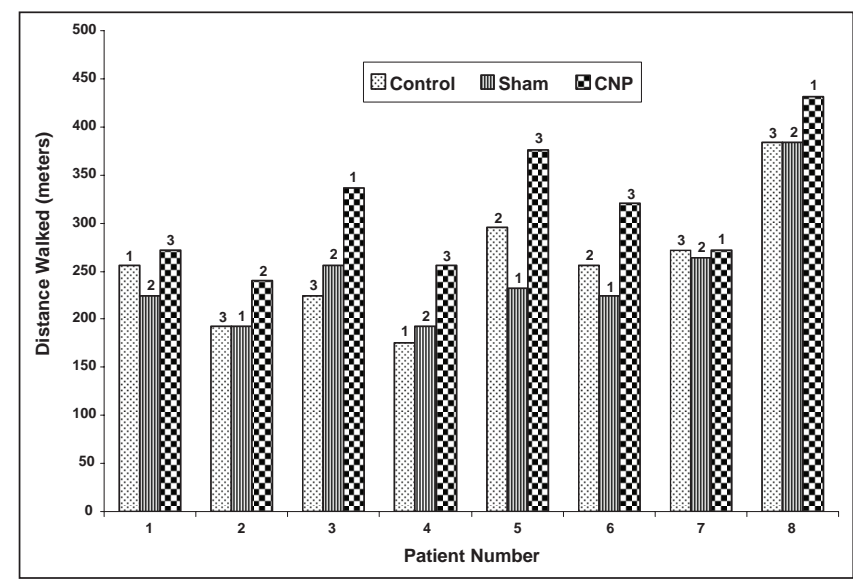

Figure 2) Distance walked in 6 min with different modes of ventilation. CNP Continuous negative pressure

These results should be interpreted with caution because only a small number of patients were studied, and the fact that the investigator encouraging the patient to 'walk as quickly as possible' was not blinded to whether sham CNP or true CNP was applied. Patients did not practice the $6 \mathrm{~min}$ walk test before the actual experiment day because it was anticipated that randomization of the order of the walk tests would eliminate any 'learning effect' (14). In addition, CNP was chosen at a level at which the patient was most comfortable breathing at rest. It is possible that the amount of negative pressure could have been further optimized during exercise because PEEPi may increase with exercise and RR $(4,5)$. It is uncertain whether CNP impedes expiration. To the extent that dynamic collapse of the airways might occur in COPD during expiration, this would minimize any effect of the CNP impeding expiration (15).

CNP with a shell and jacket is hemodynamically different from CNP using an 'iron lung'. When the entire body is enclosed in a subatmospheric chamber with the airway opening exposed to atmospheric pressure, it is equivalent to positive pressure. In an iron lung, only the head and airway opening are exposed to atmospheric pressure. This situation more closely resembles positive airway pressure than that of negative pressure surrounding only the chest wall and upper abdomen. We previously showed that with positive pressure ventilation with positive end-expiratory pressure, that the reduction in cardiac output was similar to iron lung negative pressure ventilation with negative end-expiratory pressure, unlike grid and wrap ventilation negative-pressure ventilation with a negative endexpiratory pressure (16). Thus, CNP with a shell and jacket differs from a iron lung not only with respect to hemodynamics, but also to the potential mechanism of reducing the threshold load in COPD as shown in Figure 1.

The results of the present pilot study are provocative, and CNP may prove to be a new method of enabling COPD patients to increase their exercise capability. A larger study needs to be performed with actual measurements of PEEPi. If the results are similar to the current study, technology to provide a portable source of energy can be developed and, with construction of a lightweight shell and jacket, engineered to provide CNP for COPD patients during exercise.

DISCLOSURE: This research study was funded by the Respiratory Health Network of Centres of Excellence.

ACKNOWLEDGEMENT: The authors acknowledge the statistical assistance given by Dr Sameena Iqbal. 


\section{REFERENCES}

1. Schuessler TF, Gottfried SB, Bates JH. A model of the spontaneously breathing patient: Applications to intrinsic PEEP and work of breathing. J Appl Physiol 1997;82:1694-703.

2. Haluszka J, Chartrand DA, Grassino AE, et al. Intrinsic PEEP and arterial $\mathrm{PCO}_{2}$ in stable patients with chronic obstructive pulmonary disease. Am Rev Respir Dis 1990;141:1194-7.

3. Aldrich TK, Hendler JM, Vizioli LD, et al. Intrinsic positive end expiratory pressure in ambulatory patients with airways obstruction. Am Rev Respir Dis 1993;147:845-9.

4. El Khawand CH, Vanpee D, Rousseau L, et al. Breathing frequency and use of expiratory muscles do influence the dynamic positive end-expiratory pressure. Respir Med 2003;97:388-92.

5. Thorevska NY, Manthous CA. Determinants of dynamic hyperinflation in a bench model. Respir Care 2004;49:1326-34.

6. O'Donnell DE, Sanii R, Younes M. Improvement in exercise endurance in patients with chronic airflow limitation using continuous positive airway pressure. Am Rev Respir Dis 1988;138:1510-4

7. Chaturvedi RK, Chen R, Zidulka A. Continual negative pressure versus continual positive airways pressure for chronic obstructive pulmonary disease exacerbation requiring intensive care unit admission. Chest 1996;110:180s.
8. Cumming G. A recording bag-in-a-box spirometer. J Appl Physiol 1966;21:291-2.

9. Borg GA. Psychophysical bases of perceived exertion. Med Sciv Sports Exerc 1982;14:377-81.

10. Verbraecken J, Willemen M, De Cock W, et al. Continuous positive airway pressure and lung inflation in sleep apnea patients. Respiration 2001;68:357-64

11. Petrof BJ, Calderini E, Gottfried SB. Effect of CPAP on respiratory effort and dyspnea during exercise in severe COPD. J Appl Physiol 1990;69:179-88.

12. Vieira SR, Puybasset L, Richecoeur J, et al. A lung computed tomographic assessment of positive end-expiratory pressure-induced lung overdistension. Am J Respir Crit Care Med 1998;158:1571-7.

13. Harvey LA, Ellis ER. The effect of continuous positive airway pressures on lung volumes in tetraplegic patients. Paraplegia 1996;34:54-8.

14. Wu G, Sanderson B, Bittner V. The 6-minute walk test: How important is the learning effect? Am Heart J 2003;146:129-33.

15. Koulouris NG, Valta P, Lavoie A, et al. A simple method to detect expiratory flow limitation during spontaneous breathing. Eur Respir J 1995;8:306-13.

16. Lockhat D, Langleben D, Zidulka A. Hemodynamic differences between continual positive and two types of negative pressure ventilation. Am Rev Respir Dis 1992;146:677-80. 


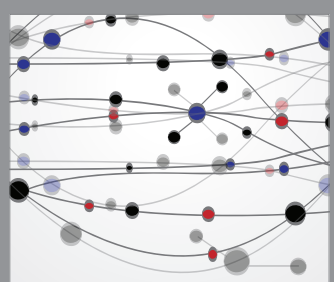

The Scientific World Journal
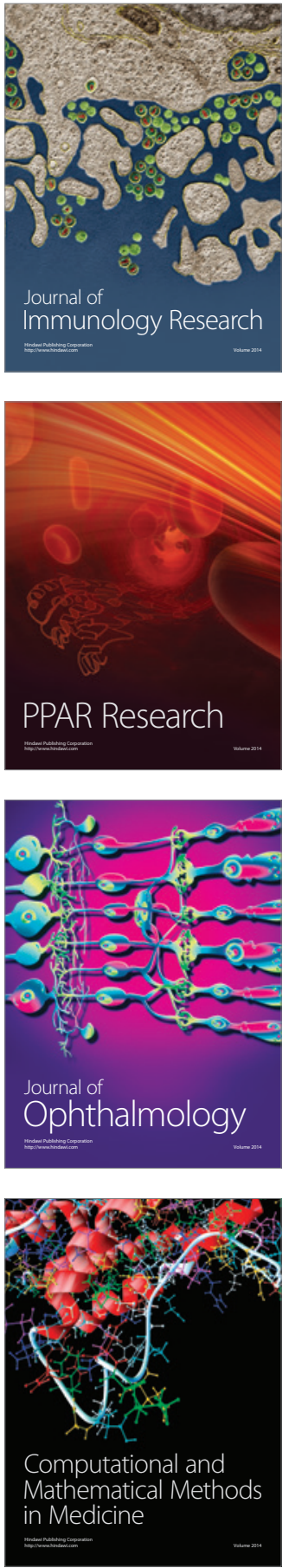

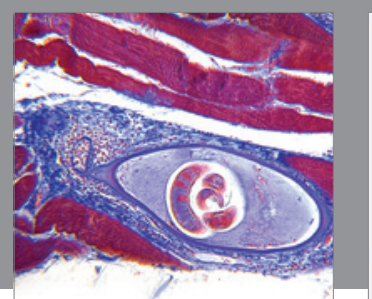

Gastroenterology Research and Practice

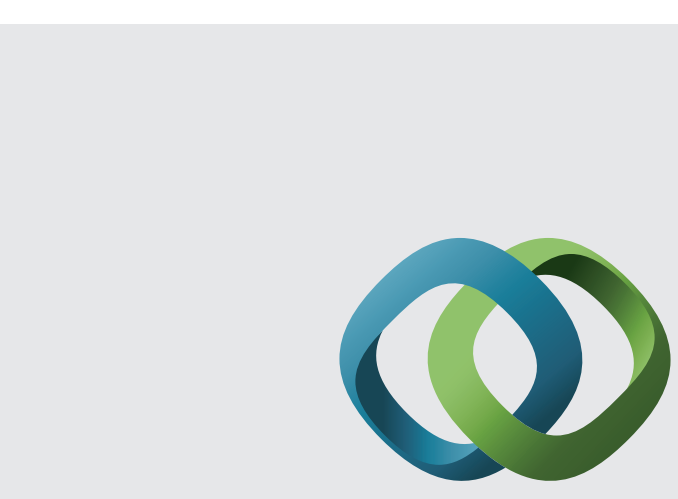

\section{Hindawi}

Submit your manuscripts at

http://www.hindawi.com
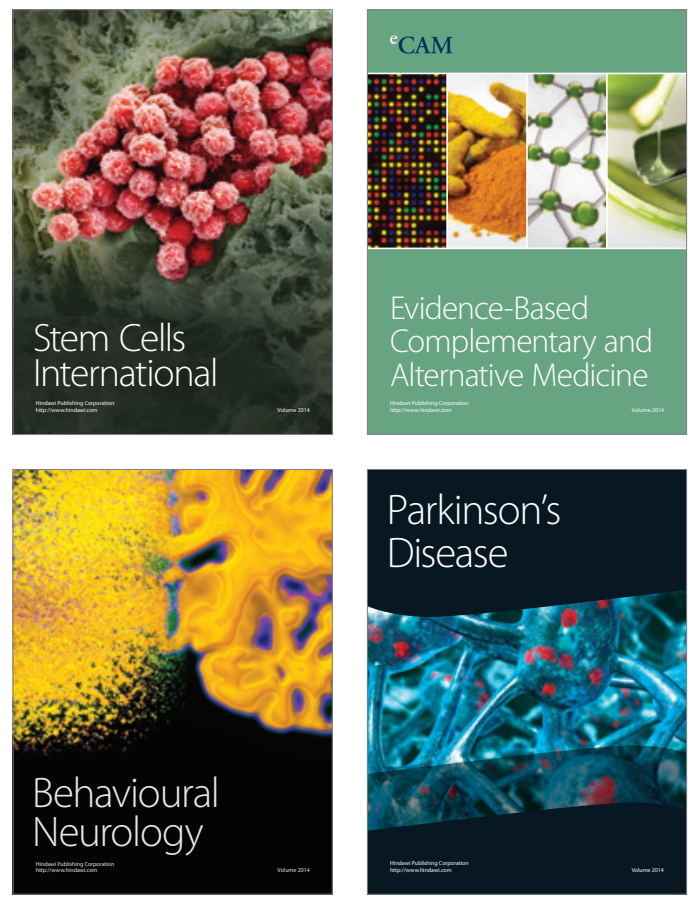
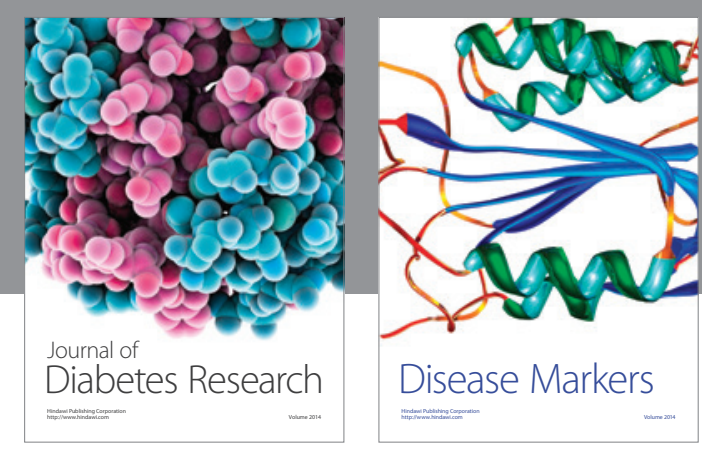

Disease Markers
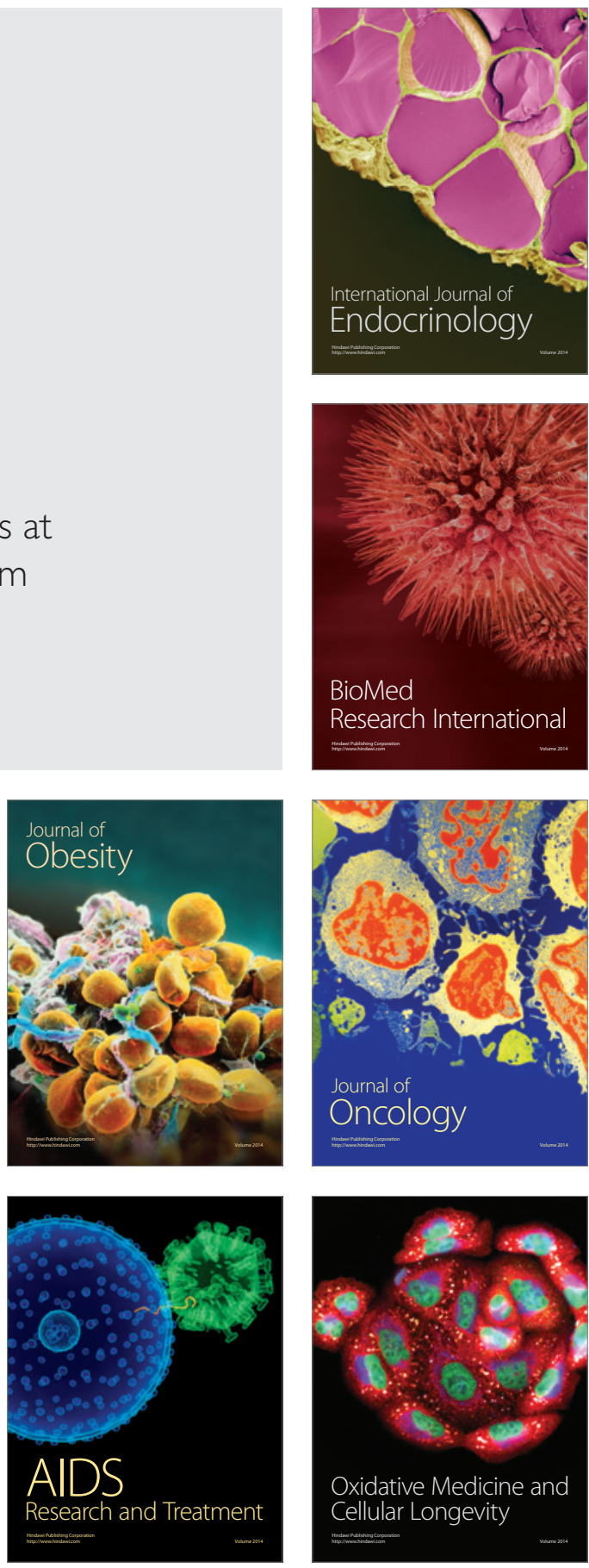